\title{
MODELAGEM DINÂMICA ESPACIAL DAS ALTERAÇÕES DE COBERTURA E USO DA TERRA RELACIONADAS À EXPANSÃO CANAVIEIRA
}

\author{
Spatial dynamic modeling of land cover and land use change associated with the \\ sugarcane expansion \\ RODRIGO DE CAMPOS MACEDO \\ CLÁUDIA MARIA DE ALMEIDA \\ JOÃO ROBERTO DOS SANTOS \\ BERNARDO FRIEDRICH THEODOR RUDORFF
}

Instituto Nacional de Pesquisas Espaciais. Av. dos Astronautas, Caixa Postal 515CEP: 12245-970. São José dos Campos - SP, Brasil

\{macedo;almeida;jroberto;bernardo\}@dsr.inpe.br

\begin{abstract}
RESUMO
A avaliação das mudanças na paisagem é fundamental para a eficiência na gestão territorial. O objetivo deste trabalho é parametrizar e calibrar um modelo de mudança de cobertura e uso, além de validar as simulações associadas à expansão canavieira em Arealva-SP, no período compreendido entre 2005 e 2010. Os mapas inicial e final foram corregistrados e, após a rasterização, foi realizada uma tabulação cruzada, gerando-se um mapa de mudanças e a respectiva matriz de transição. O modelo adotado foi o Dinamica EGO, e seu desempenho foi avaliado por meio de um método baseado no conceito de incerteza de localização (fuzziness of location), no qual a representação de uma célula é influenciada por ela mesma, e, em menor magnitude, pela sua vizinhança. Há predominância de pastagens e baixo índice de área de vegetação nativa. As mudanças mais relevantes estão relacionadas à expansão canavieira e à retração de pastagens. O valor da similaridade fuzzy entre o mapa simulado e o mapa-referência, para a janela de tamanho 11x11 e função de decaimento constante, foi de 0.52 . Foi possível aprimorar o conhecimento dos fatores direcionadores das mudanças de cobertura e uso, propiciando a revelação das forçantes dessas mudanças.

Palavras-chave: Detecção de Mudanças; Modelagem Dinâmica Espacial; Cana-deAçúcar; Dinamica EGO.
\end{abstract}




\section{ABSTRACT}

The assessment of changes in the landscape is the efficiency key in land management. The goal of this work is to parameterize and calibrate a model of land cover and land use change, and validate the predictive scenarios associated with sugarcane expansion in Arealva-SP, from 2005 to 2010. The initial and final maps were co-registered and, after rasterization, we conducted a cross-tabulation, generating a map of changes and the respective transition matrix. The model adopted was Dinamica EGO and its performance was evaluated by means of a method based on the concept of fuzziness of location, in which the representation of a cell is influenced by itself, and to a lesser extent, by its neighborhood. There is a predominance of pastures and a reduced presence of native vegetation. The most relevant changes are related to sugarcane expansion and reduction of pastures. The value of the fuzzy similarity index extracted for the comparison between the simulated map and the reference-map for a window size of 11x11 pixels and using a constant decay function was 0.52 . This simulation experiment enabled us to acquire a deeper knowledge on the drivers of land cover and land use change.

Keywords: Change Detection; Spatial Dynamic Modeling; Sugarcane; Dinamica EGO.

\section{INTRODUÇÃO}

A avaliação das mudanças na paisagem é fundamental para a eficiência na gestão territorial, pois pode subsidiar tomadas de decisões relacionadas ao uso e conservação de recursos naturais e ambientais. Para auxiliar no entendimento dessas alterações, a paisagem é comumente subdividida em classes de cobertura e uso da terra. A cobertura da terra está relacionada ao estado biofísico da superfície terrestre e seu subsolo imediato. O uso da terra diz respeito à finalidade para qual a terra é usada pela população humana local (TURNER II et al., 1995; LAMBIN et al., 2000).

Alterações de cobertura e uso da terra significam mudanças nas suas proporções e, ao mensurar essas transformações no tempo e espaço, é possível obter potenciais indicadores-chaves, pois agregam diversos aspectos bióticos e abióticos. É recomendável que a avaliação de alteração de cobertura e uso da terra seja espacialmente explícita e inclua o diagnóstico das transformações pretéritas, bem como o prognóstico das alterações futuras (MEYER \& TURNER II, 1996).

O diagnóstico das transformações pretéritas pode ser realizado a partir da detecção de mudanças ocorridas em um determinado período. Há diversas técnicas disponíveis. Dentre elas, a comparação temática direta entre duas datas é uma das mais utilizadas. Cada data requer um mapa de cobertura e uso, e a capacidade de detectar as mudanças depende do nível de qualidade deste mapa (MAS, 1999).

O prognóstico das alterações futuras é realizado através da modelagem das mudanças de cobertura e uso da terra. O modelo deve começar com um entendimento teórico do comportamento humano em relação a diferentes tipos de 
usos da terra e à distribuição destas terras no território (GEOGHEGAN et al., 1998). IGBP/IHDP (1999) ressaltam que estudos de mudanças deveriam integrar três tradições epistemológicas: i) observar e descrever para entender (abordagem indutiva); ii) modelar para entender (abordagem dedutiva); e iii) integrar para entender (abordagem dialética). De acordo com a finalidade dos modelos, Briassoulis (2000) sugeriu seis tipos de objetivos: descrever, explicar, prever, mensurar impactos ambientais, prescrever e avaliar a própria alteração da paisagem.

Além da finalidade e da epistemologia, os modelos podem ser classificados quanto à incorporação de efeitos probabilísticos. Modelos determinísticos estabelecem relações funcionais entre as variáveis e sempre se comportam da mesma forma para uma dada situação inicial. Alguns exemplos: BASS II, STARLOGO, SACI, REPAST, PCRASTER e MICE. Modelos estocásticos consideram a chance de ocorrência de vários eventos ao longo do tempo, pressupondo efeitos probabilísticos. Alguns exemplos: SLEUTH, SimLucia, CLUES, DINAMICA EGO (BURROUGH, 1998; LAMBIN et al., 2000). Perez-Vega et al. (2012), ao compararem os modelos Dinamica EGO e Land Change Modeler, perceberam que há distinções quanto ao desempenho do modelo para representar transições em nível local e em nível regional ou global.

A acoplagem de modelos de escalas distintas, tanto temporal quanto espacial, ampliam as aplicações de modelagem de mudanças de cobertura e uso da terra. Briner et al. (2012) avaliaram os impactos oriundos de variáveis climáticas e econômicas em região montanhosa dos Alpes Suiços. Britz et al. (2011) analisaram as conversões de cobertura e uso no continente europeu. Além de acoplagens, a junção de técnicas de análise espacial e geoestatística podem potencializar ainda mais as aplicações de modelagem. Freitas et al. (2013) utilizaram uma combinação de análise de correspondência canônica, modelos de regressão espacial linear e local e procedimentos de aglomeração espacial (SKATER), para aprimorar a modelagem de processos de transição de cobertura e uso na bacia do Alto Uruguai, contemplando variáveis biofísicas e socioeconômicas.

Através de modelagem, é possível propor cenários prospectivos, os quais podem representar a continuidade das alterações pretéritas (cenários estacionários), simular alterações prescritas (cenários prescritivos), ou ainda, explorar diferentes conjecturas político-socioeconômicas (cenários exploratórios não-estacionários).

Cenários estacionários utilizam o diagnóstico das alterações pretéritas para direcionar as alterações que ocorrerão no futuro. São cenários que reproduzem o que ocorreu no passado ${ }^{1}$. Devido a esta característica, são dependentes do nível de qualidade da detecção de mudanças. Podem ser propostos por meio de modelos markovianos simples conjugados a autômatos celulares, auxiliando na avaliação das alterações de cobertura e uso da terra (COUCLELIS, 2002).

Modelos que utilizam autômatos celulares são modelos matemáticos para sistemas naturais complexos. São considerados sistemas dinâmicos discretos,

${ }^{1}$ Business as usual. 
relativamente simples em sua construção e capazes de reproduzir comportamento emergente (WOLFRAM, 1984). Apresentam quatro elementos: célula, estado, vizinhança e regras de transição. A célula é a unidade espacial do modelo e está relacionada à resolução espacial, podendo ter forma regular ou ser uma feição como ponto, linha ou polígono. $\mathrm{O}$ estado é o atributo discreto de cada célula em um determinado passo de tempo e está relacionado à sua condição. É resultado não somente da influência das células vizinhas, mas principalmente das regras de transição. A vizinhança é assimilada através de uma janela móvel, cuja dimensão e formato definirá o grau de influência das células vizinhas. As regras de transição referem-se às condições para a alteração dos estados celulares ao longo do tempo, que por sua vez, é discretizado em passos (BATTY, 1998).

Devido ao rigor metodológico, modelos com autômatos celulares apresentam certas limitações para representar a realidade, porém possuem elevado desempenho computacional e estrutura espacial articulável com sistema de informações geográficas (ALMEIDA, 2003). Eles oferecem muitas possibilidades para se abstrair padrões, ordem e tendências dinâmicas prevalecentes em processos do mundo real (BATTY, 1976; OPENSHAW, 1998). Maeda et al. (2011) utilizaram um modelo baseado em autômatos celulares (Dinamica EGO) para analisar os processos de conversão florestal ocorridos no Parque Nacional do Xingu, obtendo bons resultados quanto à calibração e validação.

Essa proposição de cenários envolve diversas escolhas, que vão desde a adoção do modelo, dos dados e das variáveis, a definição das resoluções espacial e temporal, a definição quanto à estacionariedade e quanto às regras de transição. Devido à impossibilidade para se validar um cenário futuro, torna-se fundamental a calibração, ou seja, a geração de simulações pretéritas e sua consequente comparação com referências conhecidas.

O problema exposto aqui é relacionado à otimização de variáveis e parâmetros por meio de calibração. Visando evitar uma análise somente teórica - e um tanto quanto abstrata - é necessário desenvolver um estudo de caso nos moldes de um experimento empírico.

Dentre tantas possibilidades de alterações na cobertura e uso da terra, optou-se pela expansão canavieira. Nos últimos anos, o estado de São Paulo concentrou a maior parte do crescimento de lavouras de cana-de-açúcar. O objetivo deste trabalho é parametrizar e calibrar um modelo de simulação de mudanças de cobertura e uso da terra, destinado a gerar simulações anuais de expansão da cultura canavieira em áreas de vegetação nativa e pastagem no município de Arealva-SP, no período compreendido entre 2005 e 2010.

\section{MATERIAL E MÉTODOS}

\section{1 Área de estudo}

A área de estudo (Figura 1) é o município de Arealva, localizada na região centro-oeste do estado de São Paulo, às margens do Rio Tietê $\left(22^{\circ} 01^{\prime} 44,40 "\right.$ S, 
4854'39,60" O), estando a uma altitude média de 445 m, com uma área de 505 km² (IBGE, 2011a).

Figura 1 - Localização da área de estudo (em vermelho). Fonte: Wikipedia (2013).

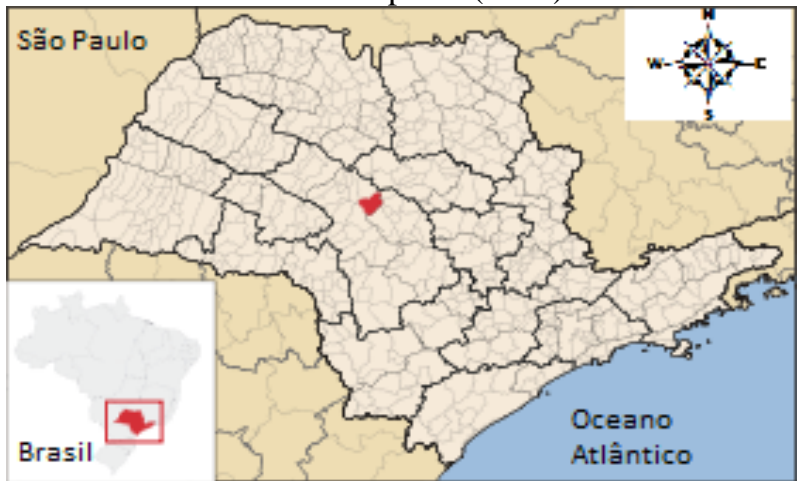

O clima é considerado tropical de altitude (Aw), sub úmido (C), mesotérmico (B’), caracterizado pela ocorrência de uma estação seca durante o ano. O verão apresenta-se com alto índice de umidade do ar e temperaturas elevadas (média de $24,3^{\circ} \mathrm{C}$ ). O inverno é frio e seco (média de $18,9^{\circ} \mathrm{C}$ ), não ultrapassando nove dias com chuvas em toda a estação. Esse clima favorece o desenvolvimento de todas as culturas de clima tropical que possuem seu desenvolvimento vegetativo de setembro a fevereiro. A média pluviométrica registrada no período 2000-2010 foi de 1.500 mm anuais (AREALVA, 2010).

O município está localizado no Planalto Ocidental Paulista, apresentando relevo suave ondulado, com declividade predominante de 3 a $8 \%$, propiciando a prática de atividades agrícolas mecanizadas e semimecanizadas (AREALVA, 2010).

Em relação aos aspectos geológicos, Arealva está inserida do Grupo Bauru, com presença de rochas sedimentares, principalmente arenitos. Os minerais originaram diversos tipos de solos, tais como latossolo vermelho distrófico, latossolo vermelho-amarelo, argissolo vermelho-amarelo e argissolo abrupto (SÃO PAULO, 2000). Com exceção dos latossolos, todos os demais apresentam susceptibilidade à erosão, principalmente do tipo laminar (AREALVA, 2010). A presença de solos rasos e o relevo suave ondulado influenciam na classificação de grande parte do município como alta susceptibilidade à erosão, principalmente na parte oeste (SÃO PAULO, 2000).

Quanto à hidrografia, o principal curso d’água é o Rio Tietê, onde deságua a maioria dos rios e córregos do município. Em termos gerais, a água utilizada no meio rural para consumo humano e dessedentação de animais provém de poços comuns e semiartesianos. Já a água utilizada para irrigação provém da captação de córregos e, principalmente, do Rio Tietê (AREALVA, 2010). 
Arealva encontra-se em uma região de fronteira entre Cerrado e Mata Atlântica, e sua flora apresenta pequena diversidade de espécies, distribuídas em fragmentos isolados (AREALVA, 2010).

Os principais usos do solo são: pastagens (60,16\%); cultura temporária (20,81\%); vegetação nativa $(9,25 \%)$; cultura perene $(5,94 \%)$, e reflorestamento (2,39\%) (SÃO PAULO, 2008a). Atualmente, as principais culturas desenvolvidas no município são as pastagens (principalmente para o desenvolvimento da atividade de pecuária de corte e pecuária de leite), a cultura da cana de açúcar, o cultivo de grãos (principalmente milho, soja, girassol e sorgo) e a olericultura em ambiente protegido, principalmente com o cultivo da cultura do pimentão (SÃO PAULO, 2008a).

\subsection{Dados utilizados}

A Tabela 1 sintetiza os dados utilizados, incluindo sua tipologia, ano-base, finalidade e referência para a geração dos mapas de cobertura e uso inicial (2005) e final (2010), bem como para a execução das simulações.

Tabela 1 - Dados utilizados, indicando-se o tipo, a data de referência, a finalidade e a referência bibliográfica.

\begin{tabular}{|c|c|c|c|c|}
\hline Dado & Tipo & Ano-Base & Finalidade & Referência \\
\hline 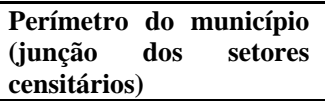 & Polígono & 2010 & $\begin{array}{l}\text { Delimitação da área de } \\
\text { influência direta. }\end{array}$ & IBGE, 2011a \\
\hline Corpos dágua & Polígono & 2010 & $\begin{array}{l}\text { Composição da classe } \\
\text { “corpos dágua” nos } \\
\text { mapas inicial e final. }\end{array}$ & $\begin{array}{l}\text { SÃO PAULO, } \\
2011\end{array}$ \\
\hline Mancha urbana & Polígono & 2010 & $\begin{array}{l}\text { Composição da classe } \\
\text { “mancha urbana” nos } \\
\text { mapas inicial e final. }\end{array}$ & IBGE, 2011b \\
\hline $\begin{array}{l}\text { Mapeamento da cana-de- } \\
\text { açúcar }\end{array}$ & Polígono & $2005 / 2010$ & $\begin{array}{l}\text { Composição da classe } \\
\text { “cana-de-açúcar” nos } \\
\text { mapas inicial e final. }\end{array}$ & INPE, 2011a \\
\hline $\begin{array}{l}\text { Mapa de uso e ocupação } \\
\text { do estado de São Paulo }\end{array}$ & Polígono & 2005 & $\begin{array}{l}\text { Composição das classes } \\
\text { “vegetação nativa”, } \\
\text { “outras culturas”, } \\
\text { “pastagem” } \\
\text { "reflorestamento" no } \\
\text { mapa inicial. }\end{array}$ & $\begin{array}{l}\text { SÃO PAULO, } \\
2009\end{array}$ \\
\hline $\begin{array}{l}\text { Zoneamento } \\
\text { agroecológico da cana- } \\
\text { de-açúcar }\end{array}$ & Polígono & 2008 & $\begin{array}{l}\text { Composição das classes } \\
\text { “outras culturas”, } \\
\text { “pastagem” } \\
\text { "reflorestamento" no } \\
\text { mapa final. }\end{array}$ & $\begin{array}{l}\text { Manzatto et al., } \\
2009\end{array}$ \\
\hline $\begin{array}{l}\text { Inventário florestal da } \\
\text { cobertura vegetal nativa } \\
\text { do estado de São Paulo }\end{array}$ & Polígono & 2009 & $\begin{array}{l}\text { Composição da classe } \\
\text { “vegetação nativa” no } \\
\text { mapa final. }\end{array}$ & $\begin{array}{l}\text { SÃO PAULO, } \\
2010 \text { (no prelo) }\end{array}$ \\
\hline Malha viária & Linha & 2010 & $\begin{array}{lll}\text { Geração } & \text { de variável } \\
\text { contínua } & \text { (distância às }\end{array}$ & IBGE, 2011b \\
\hline
\end{tabular}

Bol. Ciênc. Geod., sec. Artigos, Curitiba, v. 19, nº 2, p.313-337, abr-jun, 2013. 


\begin{tabular}{|c|c|c|c|c|}
\hline & & & $\begin{array}{l}\text { estradas) na execução } \\
\text { das simulações. }\end{array}$ & \\
\hline Malha hidrográfica & Linha & n.a & $\begin{array}{lr}\text { Geração de variável } \\
\text { contínua (distâncias aos } \\
\text { cursos d’água) na } \\
\text { execução } & \text { das } \\
\text { simulações. } & \\
\end{array}$ & $\begin{array}{l}\text { SÃO PAULO, } \\
2011\end{array}$ \\
\hline Mapa pedológico & Polígono & 1982 & $\begin{array}{l}\text { Geração de variável } \\
\text { categórica na execução } \\
\text { das simulações. }\end{array}$ & $\begin{array}{l}\text { ALMEIDA et al., } \\
1982\end{array}$ \\
\hline Declividade e Altitude & Raster & 2000 & $\begin{array}{l}\text { Geração de variável } \\
\text { categórica na execução } \\
\text { das simulações. }\end{array}$ & INPE, 2011b \\
\hline
\end{tabular}

\subsection{Aplicativos utilizados}

A Tabela 2 relaciona os aplicativos utilizados e sua finalidade.

Tabela 2 - Aplicativos utilizados, indicando-se a finalidade.

\begin{tabular}{l|l}
\hline \multicolumn{1}{c|}{ Aplicativo } & \multicolumn{1}{c}{ Finalidade } \\
\hline ARCPAD v. 7.1 & Levantamento de campo \\
\hline ARCGIS v. 10 & $\begin{array}{l}\text { Padronização de variáveis, tabelas, datum e projeção; edição vetorial; } \\
\text { geração dos mapas inicial e final; rasterização; edição matricial; tabulação } \\
\text { cruzada; geração das variáveis estáticas (categóricas e contínuas) }\end{array}$ \\
\hline ER MAPPER v. 7.1 & $\begin{array}{l}\text { Geração do cubo de variáveis estáticas (categóricas e contínuas); edição } \\
\text { dos nomes das camadas }\end{array}$ \\
\hline DINAMICA EGO v. 2.07 & $\begin{array}{l}\text { Geração das matrizes de transição; cálculos dos intervalos e dos pesos de } \\
\text { evidência; análise da associação ou dependência espacial entre variáveis; } \\
\text { execução das simulações; calibração e validação do modelo }\end{array}$ \\
\hline
\end{tabular}

\subsection{Procedimentos}

\subsubsection{Levantamento de campo}

O levantamento de campo foi realizado durante o mês de outubro de 2011, com duas finalidades: i) aprofundar a caracterização das classes de cobertura e uso; e ii) obter coordenadas de referência para a avaliação do mapa de cobertura e uso da terra de 2010.

A definição das classes de cobertura e uso levou em consideração a problemática relacionada à expansão canavieira. Sendo assim, foram selecionadas as classes cana-de-açúcar, pastagem, vegetação nativa, reflorestamento e outras culturas. Todas as fitofisionomias florestais e campestres foram agrupadas em uma única classe intitulada vegetação nativa, e as culturas agrícolas (com exceção da canavieira) foram agrupadas em uma única classe intitulada outras culturas. A caracterização das classes de cobertura e uso foi realizada a partir da observação e registro fotográfico.

A obtenção das coordenadas de referência para a avaliação dos mapas foi realizada com o método absoluto stop and go de levantamento, registrando-se coordenadas XYZ a cada segundo durante todo o trajeto (tracklog). Desta forma, 
foram percorridas todas as estradas e caminhos contidos na área de estudo. Foram selecionados pontos amostrais ao longo do trajeto, registrando-se os tipos de cobertura/uso, tal como recomendado por McCoy (2005).

\subsubsection{Mapas de cobertura e uso da terra}

Durante a geração dos mapas de cobertura e uso (inicial e final), foram agrupados e editados os polígonos referentes aos mapas previamente publicados. Além da tabela de atributos e tipos de variáveis, foram padronizados o datum (WGS-84) e a projeção (UTM, fuso 22S).

O mapeamento foi iniciado com a seleção das feições relacionadas à base cartográfica: perímetro do município, malhas hidrográfica e viária, corpos dágua e mancha urbana. A base cartográfica utilizada foi mantida intacta nas duas datas. Isto significa que quaisquer alterações relacionadas à mancha urbana (expansão urbana) e aos corpos d água (barragens, aterramentos etc.) não foram consideradas.

A escala da base cartográfica adotada é 1:250.000 (IBGE, 2011b). Visando utilizar um polígono referente ao perímetro municipal em escala mais detalhada, optou-se por unir os setores censitários, cuja escala aproximada é 1:50.000 (IBGE, 2011a). Com o objetivo de utilizar polígonos e linhas referentes à malha hidrográfica e corpos d’água em escala mais detalhada, optou-se por utilizar os dados do DAEE-SP, cuja escala aproximada é 1:50.000 (SÃO PAULO, 2011). Em relação às demais feições - malha viária e mancha urbana - foram mantidas as da base cartográfica (IBGE, 2011b). Após a definição da base cartográfica, foram inseridos os polígonos referentes às classes temáticas.

O mapa inicial foi formado a partir de uma adaptação do mapa de uso do solo do estado de São Paulo (SÃO PAULO, 2009), em escala 1:50.000. Essa adaptação consistiu em duas ações: i) substituição das classes mancha urbana e corpos d’água pelos polígonos definidos no parágrafo anterior; ii) inserção da classe cana-deaçúcar (INPE, 2011a), subtraindo-a da classe agricultura, resultando em uma classe denominada outras culturas.

O mapa final foi formado a partir dos seguintes polígonos: cana-de-açúcar, extraídos do mapeamento da cana-de-açúcar de 2010 (INPE, 2011a), com escala aproximada de 1:100.000; vegetação nativa, extraídos do inventário florestal da cobertura natural do estado de São Paulo (SÃO PAULO, 2010), em escala 1:50.000; reflorestamento e outras culturas, resultantes da junção das classes agricultura e silvicultura (MANZATTO et al., 2009), em escala 1:250.000, e pastagem, formados com o que restou após a definição das demais classes. Isso foi necessário pelo detalhamento insatisfatório das pastagens, em todas as fontes de dados consultadas.

Em virtude da diferença de escala, houve suavização dos polígonos oriundos dos mapeamento de escalas menos detalhadas (1:100.000 e 1:250.000). Por serem várias fontes, em diversas escalas, com diferentes níveis de detalhamento, essa junção de classes requereu esforços consideráveis em edição vetorial, notadamente em topologia de polígonos (VELDKAMP et al., 2001). Foram adotadas duas regras topológicas entre polígonos: i) não pode haver vazios; ii) não pode haver 
sobreposições. Para o preenchimento dos buracos e subtração das sobreposições, foi definida uma hierarquia entre as classes de feições, conforme indicado na Tabela 3.

Tabela 3 - Hierarquia entre as feições.

\begin{tabular}{c|c}
\hline Ordem hierárquica & Feição \\
\hline 1 & Perímetro municipal \\
\hline 2 & Mancha urbana \\
\hline 3 & Corpos d`água \\
\hline 4 & Cana-de-açúcar \\
\hline 5 & Vegetação nativa \\
\hline 6 & Outras culturas \\
\hline 7 & Pastagem \\
\hline 8 & Reflorestamento
\end{tabular}

O mapa final foi avaliado com base nos pontos levantados em campo. As coordenadas foram espacializadas em uma camada de pontos, que por sua vez, foi cruzada (overlay) com os mapas, extraindo-se os atributos referentes à classe.

Com tais informações, foi gerada a matriz de confusão, e calculados o índice Kappa (Equação 1) e a exatidão global. A exatidão global foi determinada com a divisão dos acertos (diagonal na matriz de confusão) pela quantidade total de observações. A quantidade de acertos dividida pela quantidade de observações de campo (para cada classe) é chamada de exatidão do produtor. Com ela, é possível estimar o erro de omissão. Já a quantidade de acertos dividida pela quantidade de amostras no mapa temático (para cada classe) é chamada de exatidão do consumidor. Com ela, é possível estimar o erro de comissão (JENSEN, 2005; MATHER, 2004).

$$
\hat{\mathrm{K}}=\frac{N \sum_{i=1}^{\kappa} \chi_{i i}-\sum_{i=1}^{\kappa}\left(\chi_{i+} \cdot \chi_{+i}\right)}{N^{2}-\sum_{i=1}^{\kappa}\left(\chi_{i+} \cdot \chi_{+i}\right)} .
$$

Em que:

$K=$ quantidade de linhas na matriz de confusão

$N=$ quantidade total de observações

$x_{i i}=$ quantidade de observações na linha i coluna i (diagonal)

$x_{i^{+}}=$quantidade de observações na linha i

$x_{+i}=$ quantidade de observações na coluna i

\subsubsection{Detecção de mudanças e matriz de transição}

Foi selecionada a técnica de álgebra de mapas, ou seja, comparação direta entre as camadas categóricas. Para isto, os mapas inicial (2005) e final (2010), em formato vetorial, foram corregistrados e rasterizados, adotando-se a dimensão de $400 \mathrm{~m}^{2}(20 \times 20 \mathrm{~m})$ para o pixel. Após a rasterização, foi realizada uma tabulação 
cruzada, na qual são concatenados os dois mapas, ou seja, há a geração de um mapa de mudanças e de uma matriz de transição.

A Tabela 4 expressa todas as transições possíveis e os potenciais processos de mudança de cobertura/uso associados. Para toda mudança de cobertura e uso, há, concomitantemente, dois processos relacionados: um de expansão (ou incremento) e um de retração (ou decremento). Aqueles de maior relevância para os objetivos do trabalho estão indicados com um "X”.

Tabela 4 - Mudanças potenciais de cobertura/uso e processos associados.

\begin{tabular}{|c|c|c|c|c|c|}
\hline \multicolumn{2}{|c|}{ Classe } & \multicolumn{4}{|c|}{ Processo } \\
\hline 2005 & 2010 & Incremento & & Decremento & \\
\hline Cana-de-açúcar & Vegetação nativa & $\begin{array}{l}\text { Regeneração ou } \\
\text { Readequação }\end{array}$ & $\mathrm{X}$ & $\begin{array}{l}\text { Retração } \\
\text { canavieira }\end{array}$ & \\
\hline Cana-de-açúcar & Outras culturas & Expansão agrícola & & $\begin{array}{c}\text { Retração } \\
\text { canavieira }\end{array}$ & $\mathrm{X}$ \\
\hline Cana-de-açúcar & Pastagem & Expansão pecuária & & $\begin{array}{l}\text { Retração } \\
\text { canavieira }\end{array}$ & $\mathrm{X}$ \\
\hline Cana-de-açúcar & Reflorestamento & Expansão silvícola & & $\begin{array}{l}\text { Retração } \\
\text { canavieira }\end{array}$ & $\mathrm{X}$ \\
\hline Vegetação nativa & Cana-de-açúcar & Expansão canavieira & $\mathrm{X}$ & Degradação & \\
\hline Vegetação nativa & Outras culturas & Expansão agrícola & & Degradação & $\mathrm{X}$ \\
\hline Vegetação nativa & Pastagem & Expansão pecuária & & Degradação & $\mathrm{X}$ \\
\hline Vegetação nativa & Reflorestamento & Expansão silvícola & & Degradação & $\mathrm{X}$ \\
\hline Outras culturas & Cana-de-açúcar & Expansão canavieira & $\mathrm{X}$ & Retração agrícola & \\
\hline Outras culturas & Vegetação nativa & $\begin{array}{c}\text { Regeneração ou } \\
\text { Readequação }\end{array}$ & $\mathrm{X}$ & Retração agrícola & \\
\hline Outras culturas & Pastagem & Expansão pecuária & $\mathrm{X}$ & Retração agrícola & \\
\hline Outras culturas & Reflorestamento & Expansão silvícola & & Retração agrícola & $\mathrm{X}$ \\
\hline Pastagem & Cana-de-açúcar & Expansão canavieira & $\mathrm{X}$ & Retração pecuária & \\
\hline Pastagem & Vegetação nativa & $\begin{array}{c}\text { Regeneração ou } \\
\text { Readequação }\end{array}$ & $\mathrm{X}$ & Retração pecuária & \\
\hline Pastagem & Outras culturas & Expansão agrícola & & Retração pecuária & $\mathrm{X}$ \\
\hline Pastagem & Reflorestamento & Expansão silvícola & & Retração pecuária & $\mathrm{X}$ \\
\hline Reflorestamento & Cana-de-açúcar & Expansão canavieira & $\mathrm{X}$ & Retração silvícola & \\
\hline Reflorestamento & Vegetação nativa & $\begin{array}{c}\text { Regeneração ou } \\
\text { Readequação }\end{array}$ & $\mathrm{X}$ & Retração silvícola & \\
\hline Reflorestamento & Outras culturas & Expansão agrícola & $\mathrm{X}$ & Retração silvícola & \\
\hline Reflorestamento & Pastagem & Expansão pecuária & $\mathrm{X}$ & Retração silvícola & \\
\hline
\end{tabular}

\subsubsection{Parametrização e calibração do modelo}

O modelo adotado foi o Dinamica EGO (Environment for Geoprocessing Objects) ${ }^{2}$. Trata-se de um modelo orientado a processos e passível de comportar implementações baseadas em agentes no nível macro e em modelos customizados. É um modelo aberto a diferentes parametrizações (pesos de evidência, regressão logística, redes neurais, árvore de decisão etc.), possui algoritmos de transição por

\footnotetext{
${ }^{2}$ www.csr.ufmg.br/dinamica/

Bol. Ciênc. Geod., sec. Artigos, Curitiba, v. 19, nº 2, p.313-337, abr-jun, 2013.
} 
expansão ou nucleação e algoritmo genético para definição dos melhores pesos de evidência. A matriz de transição permite o cálculo das probabilidades de transição, que por sua vez, permitem a execução de simulações pretéritas e a geração de cenários prospectivos variados.

O cálculo das probabilidades globais de transição refere-se ao total de mudanças para cada tipo de transição da cobertura da terra em um dado período de simulação sem levar em consideração as particularidades espaciais locais, que são aquelas pertencentes a cada célula da área de estudo em termos de características do sítio físico ou de infraestrutura. "De forma diversa das probabilidades globais, as probabilidades locais de transição são calculadas para cada célula e, sendo assim, consideram as especificidades naturais e antrópicas do sitio físico" (XIMENES et al., 2008). Com base nos mapas inicial e final, foram calculadas taxas de transição em um passo simples, ou seja, do período completo (5 anos) e em passos múltiplos (anualizadas), derivada de uma matriz ergódica.

Ximenes et al. (2008) salientam que a escolha adequada das variáveis explicativas é determinante para o sucesso do uso de modelos, pois com base nas suas relações com a variável dependente, são definidas as células com maior ou menor probabilidade de transição de cobertura da terra.

Foram consideradas as seguintes variáveis potenciais: proximidade da classe em expansão; proximidade dos cursos d’água, proximidade das estradas, proximidade da hidrovia (Tietê), tipos de solo e classes de declividade. Em relação a estas últimas, foi adotada a classificação presente no Manual Brasileiro para Levantamento da Capacidade de Uso (MARQUES, 1971). Apesar de haver classificações mais recentes ${ }^{3}$, essa classificação é plenamente compatível com as limitações relacionadas à mecanização do setor canavieiro. Todas as variáveis foram rasterizadas com pixels de $20 \mathrm{~m}$. Após a rasterização, foi padronizado o número de linhas e colunas de todos os insumos utilizados. As variáveis foram agrupadas em um único arquivo (cubo de variáveis estáticas).

O método de pesos de evidência possibilita analisar quais variáveis são as mais importantes em cada transição. Tal fato tem papel fundamental no entendimento do processo de mudança de cobertura e uso (GONÇALVES et al., 2007). Para categorizar as variáveis contínuas, são calculados intervalos nos mapas de distâncias, de forma semelhante a um fatiamento. Além das distâncias às estradas e cursos d'água, foram adotadas as distâncias às classes envolvidas nas transições. Esse resultado é utilizado no cálculo dos pesos de evidência, que por sua vez, são utilizados para derivar os mapas de probabilidade de transição, utilizados nas simulações (NOVAES et al., 2011). Cada transição foi tratada separadamente.

A determinação dos pesos das variáveis explicativas pressupõe a independência de eventos (Teorema de Bayes). Isto foi analisado nos resultados dos testes de independência espacial, com os seguintes índices: Cramer (V) e Joint

${ }^{3}$ Lepsch et al. (1991) e EMBRAPA (1999). 
Information Uncertainty (JIU) ${ }^{4}$. Esses índices operam com valores reais e percentuais, respectivamente, e avaliam o grau de dependência espacial entre pares de variáveis. Conforme Bonham-Carter (1994), quanto mais próximos de 1, maior a dependência espacial entre os pares de variáveis consideradas. Foram excluídas todas as variáveis com resultados acima de 0,5.

A parametrização do modelo também inclui a definição dos parâmetros dos algoritmos patcher e expander, responsáveis pela alocação de mudanças de cobertura e uso da terra. A função expander responde pela expansão de manchas previamente existentes de uma determinada classe. A função patcher, por sua vez, destina-se a gerar novas manchas, por meio de um mecanismo de constituição de sementes (SOARES-FILHO et al., 2002).

Além da proporção entre patcher e expander, são necessárias a média e variância da área de mudança, além do índice de isometria. A média e variância da área de mudança foram obtidas através da vetorização do mapa de mudanças. O índice de isometria representa um valor numérico, o qual é multiplicado pelo valor de probabilidade das células vizinhas. O grau de fragmentação das manchas é inversamente proporcional ao valor do índice (ALMEIDA et al., 2008). Foi adotado 1,5 para o índice de isometria.

\subsubsection{Validação do modelo}

Após a obtenção dos parâmetros satisfatórios, foram geradas simulações anuais a partir do mapa inicial, ou seja, de 2006 a 2010. O desempenho do modelo foi avaliado utilizando-se um método baseado no conceito de fuzziness of location $^{5}$, no qual a representação de uma célula é influenciada por ela mesma, e, em menor magnitude, pelas células na sua vizinhança (HAGEN, 2003). Trata-se de um teste de comparação de similaridade fuzzy entre o mapa simulado e o mapa-referência. O índice de similaridade fuzzy empregado neste trabalho foi criado pelo Centro de Sensoriamento Remoto da Universidade Federal de Minas Gerais (CSR/UFMG) e representa uma adaptação do índice de similaridade fuzzy criado por Hagen (2002), sendo que este último penaliza o ajuste em vista da distância da célula central, em análise, em relação à célula que contém a classe desejada na cena de comparação, utilizando uma função de decaimento, que pode ser constante ou exponencial (ALMEIDA et al., 2008). No caso particular deste trabalho, a comparação foi feita entre dois mapas-diferenças, resultantes, de um lado, da subtração entre o mapa final real e o mapa inicial, e de outro lado, entre o mapa final simulado e o mapa inicial, conforme implementado na plataforma Dinamica EGO. Adotou-se uma função de decaimento constante, calculada com os seguintes tamanhos de janelas: 1x1, 3x3, 5x5, 7x7, 9x9 e 11x11. Com o modelo validado, diversos cenários podem ser gerados, de acordo com o escopo da modelagem.

\footnotetext{
${ }^{4}$ Índice de Incerteza de Informação Conjunta.

${ }^{5}$ Incerteza de localização.

Bol. Ciênc. Geod., sec. Artigos, Curitiba, v. 19, nº 2, p.313-337, abr-jun, 2013.
} 


\section{RESULTADOS}

\subsection{Levantamento de campo}

O Tracklog realizado no município de Arealva apresentou 52.033 observações intercaladas de dois segundos, com a média de nove satélites rastreados; HDOP (Horizontal Dilution of Precision) de 0,935; VDOP (Vertical Dilution of Precision) de 1,653; PDOP (Planimetric Dilution of Precision) de 1,989. Estes parâmetros são considerados ótimos de acordo com Mikhail e Gracie (1977) e Huerta et al. (2005). A distribuição espacial dos pontos possibilitou a representação da área do município.

Ao longo desse caminhamento, foram amostradas todas as classes estabelecidas na legenda temática, podendo-se observar na Tabela 5 a quantidade de pontos amostrados por classe.

Tabela 5 - Pontos amostrados por classe.

\begin{tabular}{l|c}
\hline \multicolumn{1}{c|}{ Classe } & Quantidade de pontos \\
\hline Vegetação nativa & 60 \\
\hline Pastagem & 40 \\
\hline Cana-de-açúcar & 30 \\
\hline Outras culturas & 30 \\
\hline Reflorestamento & 10 \\
\hline Total & $\mathbf{1 7 5}$ \\
\hline
\end{tabular}

\subsection{Mapas de cobertura e uso da terra}

Os mapas de cobertura e uso da terra de Arealva - de 2005 e de 2010 - podem ser visualizados nas Figuras 2 e 3, respectivamente. Na Tabela 6, apresenta-se o cálculo de áreas (em ha e em porcentagem) das classes de ambos os mapas.

Tabela 6 - Cálculo de áreas referentes aos mapas de cobertura e uso da terra em

\begin{tabular}{|c|c|c|c|c|}
\hline \multicolumn{5}{|c|}{ Arealva. } \\
\hline \multirow[t]{2}{*}{ Classe } & \multicolumn{2}{|c|}{2005} & \multicolumn{2}{|c|}{2010} \\
\hline & ha & $\%$ & ha & $\%$ \\
\hline Pastagem & $38.904,61$ & 77,00 & $33.949,76$ & 67,19 \\
\hline Vegetação Nativa & $6.600,83$ & 13,06 & $4.597,76$ & 9,10 \\
\hline Outras Culturas & $1.673,32$ & 3,31 & $2.000,81$ & 3,96 \\
\hline Cana-de-Açúcar & $1.342,73$ & 2,66 & $7.960,57$ & 15,76 \\
\hline Corpos d’água & $1.025,30$ & 2,03 & $1.025,30$ & 2,03 \\
\hline Reflorestamento & 601,18 & 1,19 & 613,77 & 1,21 \\
\hline Mancha Urbana & 377,99 & 0,75 & 377,99 & 0,75 \\
\hline Total & $50.525,96$ & 100,00 & $50.525,96$ & 100,00 \\
\hline
\end{tabular}


Figura 2 - Mapa inicial de cobertura e uso da terra em Arealva.

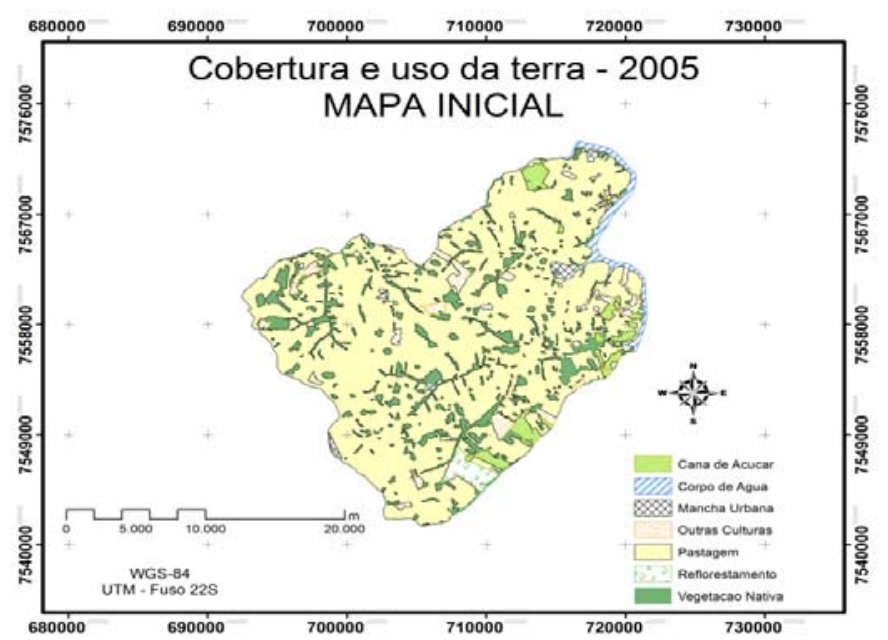

Figura 3 - Mapa final (2010) de cobertura e uso da terra em Arealva.

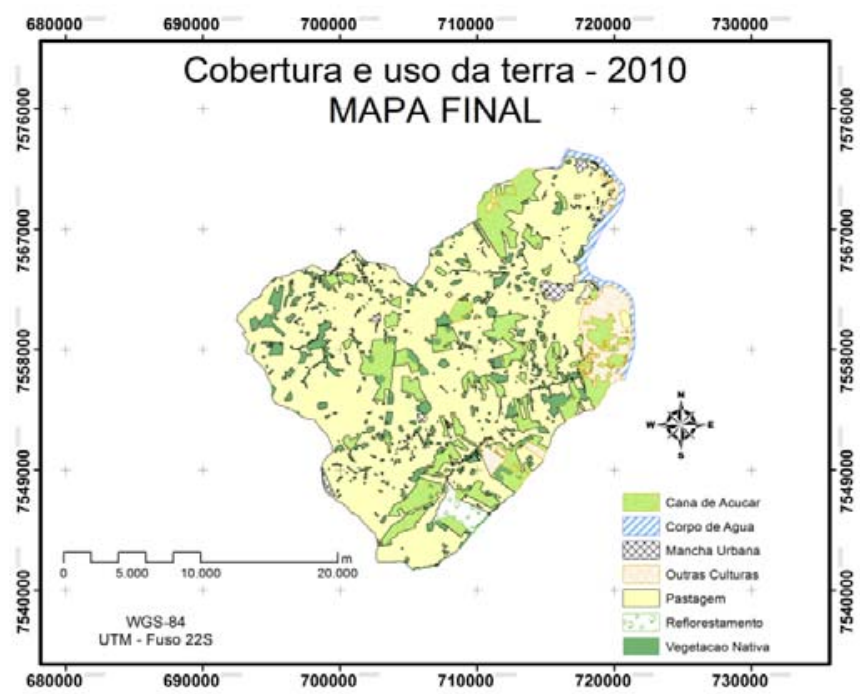

É nítida a predominância de pastagens e o baixo índice de área de vegetação nativa em Arealva. Mais de dois terços da área territorial está sendo ocupada com pecuária de leite e de corte.

Bol. Ciênc. Geod., sec. Artigos, Curitiba, v. 19, no 2, p.313-337, abr-jun, 2013. 
A matriz de confusão, a exatidão do produtor, a exatidão do consumidor e o índice Kappa referentes ao mapa de 2010 (final) podem ser visualizados na Tabela 7.

Tabela 7 - Matriz de confusão, exatidão do produtor, exatidão do consumidor e índice Kappa.

\begin{tabular}{|c|c|c|c|c|c|c|c|}
\hline \multirow{7}{*}{ 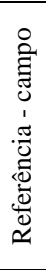 } & Classes temáticas & $\begin{array}{l}\text { Cana-De- } \\
\text { Açúcar }\end{array}$ & $\begin{array}{l}\text { Pasta- } \\
\text { Gem }\end{array}$ & $\begin{array}{l}\text { Vegetaçã } \\
\text { o Nativa }\end{array}$ & $\begin{array}{c}\text { Outras } \\
\text { Culturas }\end{array}$ & $\begin{array}{l}\text { Reflo- } \\
\text { Rest. }\end{array}$ & $\begin{array}{c}\text { Total } \\
\text { (Linha) }\end{array}$ \\
\hline & Cana-de-açúcar & 23 & 2 & 2 & 3 & 0 & 30 \\
\hline & Pastagem & 2 & 44 & 8 & 6 & 0 & 60 \\
\hline & Vegetação nativa & 5 & 8 & 23 & 4 & 0 & 40 \\
\hline & Outras culturas & 5 & 5 & 5 & 15 & 0 & 30 \\
\hline & Reflorestamento & 0 & 0 & 0 & 0 & 15 & 15 \\
\hline & Total (coluna) & 35 & 59 & 38 & 28 & 15 & 175 \\
\hline & & $\begin{array}{l}\text { Exatidão - } \\
\text { produtor }\end{array}$ & $\begin{array}{l}\text { Erros de } \\
\text { omissão }\end{array}$ & $\begin{array}{c}\text { Exatidão } \\
\text { - consu- } \\
\text { midor }\end{array}$ & $\begin{array}{l}\text { Erros de } \\
\text { comissão }\end{array}$ & & \\
\hline & Cana-de-açúcar & $65,71 \%$ & $34,29 \%$ & $76,67 \%$ & $23,33 \%$ & & \\
\hline & Pastagem & $74,58 \%$ & $25,42 \%$ & $73,33 \%$ & $26,67 \%$ & & \\
\hline & Vegetação nativa & $60,53 \%$ & $39,47 \%$ & $57,50 \%$ & $42,50 \%$ & & \\
\hline & Outras culturas & $53,57 \%$ & $46,43 \%$ & $50,00 \%$ & $50,00 \%$ & & \\
\hline & Refloresta-mento & $100,00 \%$ & $0,00 \%$ & $100,00 \%$ & $0,00 \%$ & & \\
\hline & Exatidão global & $68,57 \%$ & & & & & \\
\hline & Índice kappa & $58,96 \%$ & & & & & \\
\hline
\end{tabular}

O resultado do desempenho temático obtido é considerado baixo, mas aceitável (FOODY, 2002; 2004; PONTIUS JR., 2000; 2002). Provavelmente, este resultado aquém do esperado ocorreu principalmente devido a:

- diferenças de escala entre os insumos utilizados;

- fragmentação dos remanescentes de vegetação nativa. A diferença na dimensão dos polígonos referentes à vegetação nativa é significativa. Em geral, são pequenas ilhas de vegetação em meio à agropecuária.

\subsection{Detecção de mudanças e matriz de transição}

Após a geração dos mapas inicial e final, foram calculadas as alterações ocorridas no período 2005-2010, agregadas por classe, como pode ser visualizado na Tabela 8.

As mudanças mais relevantes estão relacionadas à expansão canavieira e retração de pastagens. A área plantada com cana-de-açúcar quase sextuplicou, enquanto que a área de pastagem diminuiu cerca de 5.000 ha. Outra mudança relevante é a diminuição de vegetação nativa, porém isto se deve às diferenças metodológicas entre o mapa de uso e ocupação do estado de São Paulo (SÃO PAULO, 2009) e o inventário florestal da vegetação natural do estado de São Paulo, 2001-2002 (KRONKA et al., 2005). 
Tabela 8 - Alterações de cobertura e uso da terra agregadas por classe.

\begin{tabular}{l|l|l|l}
\hline \multirow{2}{*}{ Classe } & \multicolumn{3}{c}{ Mudanças (2005 - 2010) } \\
\cline { 2 - 4 } & \multicolumn{1}{|c}{ Ha } & \multicolumn{1}{c}{${ }^{(1)} \%$} & \multicolumn{1}{c}{$\%$} \\
\hline Cana-de-Açúcar & $6.617,84$ & 47,56 & 492,86 \\
\hline Pastagem & $-4.954,85$ & 35,61 & $-12,74$ \\
\hline Vegetação Nativa & $-2.003,07$ & 14,39 & $-30,35$ \\
\hline Outras Culturas & 327,49 & 2,35 & 19,57 \\
\hline Reflorestamento & 12,59 & 0,09 & 2,09 \\
\hline Mancha Urbana & 0,00 & 0,00 & 0,00 \\
\hline Corpos d`água & 0,00 & 0,00 & 0,00 \\
\hline${ }^{(3)}$ Total & $13.915,84$ & 100,00 & 27,54 \\
\hline${ }^{(4)}$ Mudanças agregadas
\end{tabular}

(1) - Percentual de mudanças em relação ao total de mudanças.

(2) - Percentual de mudanças em relação à classe.

(3) - Totalização de mudanças em módulo, ou seja, independentemente de expansão ou retração.

(4) - Percentual de mudanças em relação à área total do município.

A desagregação das alterações de cobertura e uso foi expressa em uma matriz de transição (Tabela 9), possibilitando a mensuração dos processos de mudanças de cobertura e uso da terra (Tabela 10).

Tabela 9 - Alterações de cobertura e uso da terra desagregadas.

\begin{tabular}{l|l|l|r|r}
\hline \multicolumn{1}{c|}{$\mathbf{2 0 0 5}$} & \multicolumn{1}{c|}{$\mathbf{2 0 1 0}$} & \multicolumn{1}{c|}{ Processo } & \multicolumn{1}{c}{ ha } \\
\hline Pastagem & Cana-de-açúcar & Expansão canavieira & $6.247,15$ & 44,89 \\
\hline Vegetação nativa & Pastagem & Degradação & $2.853,83$ & 20,51 \\
\hline Pastagem & Outras culturas & Retração pecuária & $1.385,86$ & 9,96 \\
\hline Pastagem & Vegetação nativa & $\begin{array}{l}\text { Regeneração } \\
\text { Readequação }\end{array}$ & $1.317,39$ & 9,47 \\
\hline Outras culturas & Pastagem & Expansão pecuária & $1.002,39$ & 7,20 \\
\hline Vegetação nativa & Cana-de-açúcar & Expansão canavieira & 334,13 & 2,40 \\
\hline Outras culturas & Cana-de-açúcar & Expansão canavieira & 328,30 & 2,36 \\
\hline Vegetação nativa & Outras culturas & Degradação & 243,75 & 1,75 \\
\hline Cana-de-açúcar & Pastagem & Retração canavieira & 76,69 & 0,56 \\
\hline Cana-de-açúcar & Outras culturas & Retração canavieira & 65,73 & 0,47 \\
\hline Outras culturas & Vegetação nativa & $\begin{array}{l}\text { Regeneração } \\
\text { Readequação }\end{array}$ & 24,65 & 0,18 \\
\hline Cana-de-açúcar & Vegetação nativa & $\begin{array}{l}\text { Regeneração } \\
\text { Readequação }\end{array}$ & 10,96 & 0,08 \\
\hline Pastagem & Reflorestamento & Retração pecuária & 10,96 & 0,08 \\
\hline Vegetação nativa & Reflorestamento & Degradação & 9,59 & 0,07 \\
\hline Reflorestamento & Cana-de-açúcar & Expansão canavieira & 2,74 & 0,02 \\
\hline Reflorestamento & Vegetação nativa & $\begin{array}{l}\text { Regeneração } \\
\text { Readequação }\end{array}$ & 1,37 & 0,01 \\
\hline Total & & & $\mathbf{1 3 . 9 1 5 , 8 4}$ & $\mathbf{1 0 0 , 0 0}$ \\
\hline
\end{tabular}

Bol. Ciênc. Geod., sec. Artigos, Curitiba, v. 19, no 2, p.313-337, abr-jun, 2013. 
Tabela 10 - Processos de mudança de cobertura e uso da terra.

\begin{tabular}{l|l|l}
\multicolumn{1}{c|}{ Processo } & \multicolumn{1}{c|}{ ha } & \multicolumn{1}{c}{ \% } \\
\hline Expansão canavieira & $6.912,71$ & 49,68 \\
\hline Degradação & $3.107,16$ & 22,33 \\
\hline Retração pecuária & $1.396,81$ & 10,04 \\
\hline Regeneração ou Readequação & $1.354,36$ & 9,73 \\
\hline Expansão pecuária & $1.002,39$ & 7,20 \\
\hline Retração canavieira & 142,42 & 1,03 \\
\hline Total & $\mathbf{1 3 . 9 1 5 , 8 4}$ & $\mathbf{1 0 0 , 0 0}$ \\
\hline
\end{tabular}

Na matriz de transições, é possível perceber a expressiva conversão de pastagens em culturas agrícolas, principalmente a cana-de-açúcar. Além da conversão agrícola, houve abandono de terras anteriormente utilizadas para pecuária e atualmente em processo de regeneração. A expansão canavieira observada é compatível com o zoneamento agroecológico da cana-de-açúcar (MANZATTO et al., 2009) e com o zoneamento agroambiental do estado de São Paulo (SÃO PAULO, 2008b).

A ocorrência de processos de retração canavieira pode ser justificada por ações de manejo relacionadas à seleção de áreas mais produtivas e, consequente, liberação de áreas menos produtivas para processos de readequação ambiental.

\subsection{Parametrização e calibração do modelo}

De acordo com os resultados dos índices V e JIU no teste de dependência espacial, foi excluída a variável "distância à hidrovia", devido à redundância em relação à variável "distância aos cursos d'água”. Esta exclusão foi necessária para garantir a independência de eventos. Após a exclusão, foram recalculados os intervalos e os pesos de evidência.

Durante a calibração, foram explicitadas algumas relações entre as variáveis e as transições. Por não ser irrigada, é mais provável que a expansão canavieira ocorra distante dos cursos d'água (Figura 4A) e menos provável que expanda em argissolos (Figura 4B), ocorrendo até mesmo retração agropecuária (Figura 4C); praticamente não há expansão canavieira em locais com alta declividade (Figura 4D). Em relação à regeneração, é mais provável ocorrer em locais declivosos (Figura 4E) e em locais próximos aos fragmentos existentes (Figura 4F). Quanto à degradação, é mais provável ocorrer em locais planos, devido à pressão agropecuária (Figura 4G), em locais próximos às estradas (Figura 4H) e próximos aos cursos d'água (Figura 4I). 
Figura 4 - Relações entre algumas variáveis e transições: expansão canavieira em relação à “distância aos cursos d’água” (A); expansão canavieira em relação aos tipos de solos (B); retração de pastagem em relação à declividade (C); expansão canavieira e declividade (D); regeneração/readequação e declividade (E); regeneração/readequação em relação à “distância à vegetação nativa” (F); degradação em relação à declividade $(\mathrm{G})$; degradação em relação à “distância às estradas (H); degradação em relação à “distância aos cursos d’água” (I).

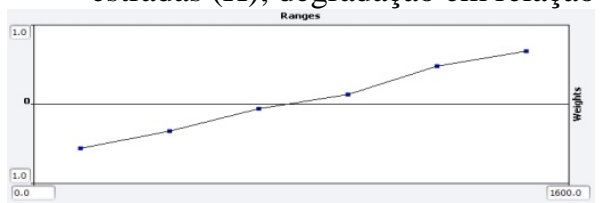

A

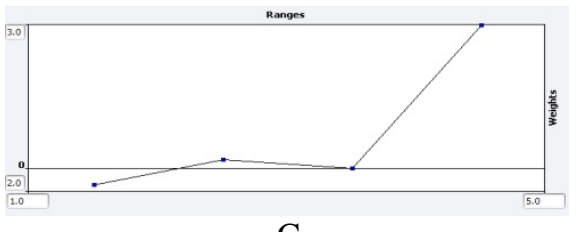

C

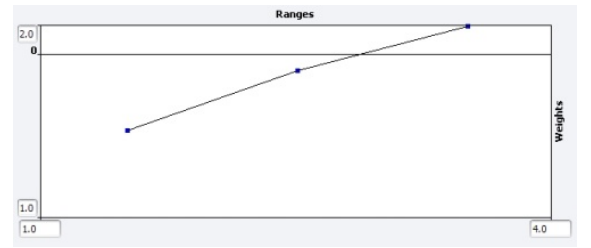

E

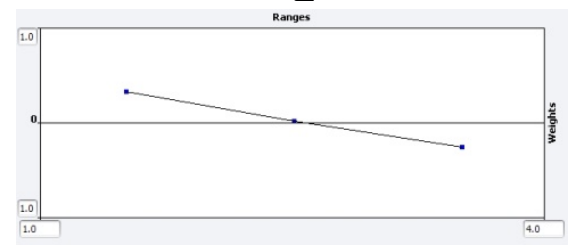

G

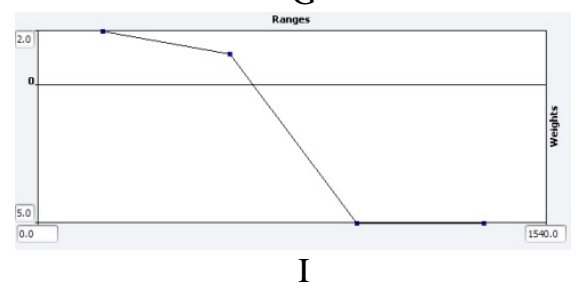

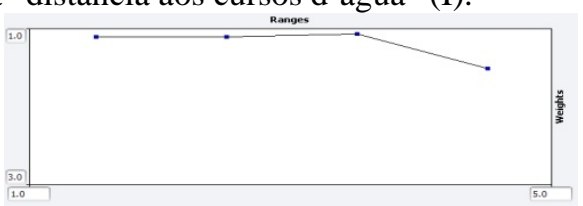

B

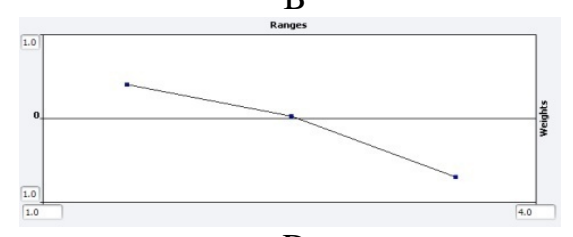

D

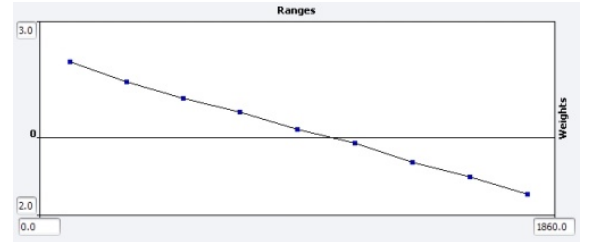

$\mathrm{F}$

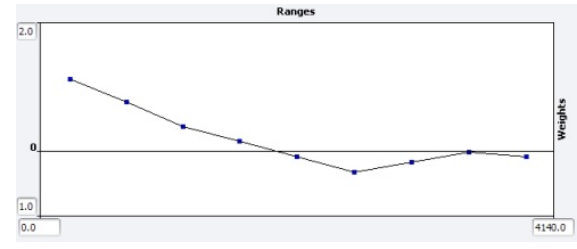

$\mathrm{H}$

Bol. Ciênc. Geod., sec. Artigos, Curitiba, v. 19, nº 2, p.313-337, abr-jun, 2013. 


\subsection{Parametrização e validação do modelo}

Processos típicos de expansão, tais como a da cana-de-açúcar, tiveram uma participação maior do algoritmo expander, enquanto que processos relacionados aos fragmentos de vegetação nativa - regeneração e degradação - tiveram uma participação maior do algoritmo patcher, visto que a maior parte da expansão canavieira se dá em áreas fronteiriças a essas lavouras, ao passo que a perturbação e/ou regeneração de fragmentos de vegetação nativa ocorre de forma difusa.

O valor da similaridade fuzzy entre o mapa simulado e o mapa-referência, para a janela de tamanho 11x11 pixels e função de decaimento constante, foi de 0.5182381698 . O índice de similaridade fuzzy adaptado não opera sobre o mapa final real e o mapa final simulado, como o originalmente criado por Hagen (2002), mas sim entre os mapas-diferença resultantes da subtração desses dois mapas do mapa inicial real. Na prática, índices de similaridade fuzzy adaptados com valores oscilando entre 0.45 e 0.50 para janelas de amostragem com tamanhos de $3 \times 3$ a $5 \times 5$ têm denotado concordâncias aceitáveis entre o mapa simulado e o mapa real, considerando-se que esse índice desconsidera as áreas de não-mudança, as quais são responsáveis por sobrestimar índices de ajuste em geral, incluindo o índice de similaridade fuzzy propriamente dito (ALMEIDA et al., 2008; SOARES-FILHO et al., 2013).

Após a obtenção dos parâmetros satisfatórios, foram gerados mapas de probabilidades e simulações anuais de 2005 até 2010. O mapa simulado de 2010 pode ser comparado com o mapa final (referência) na Figura 5.

Figura 5 - Comparação entre o mapa final real (REFERÊNCIA) e o mapa final simulado (SIMULAÇÃ̃) de cobertura e uso da terra em Arealva no ano de 2010.

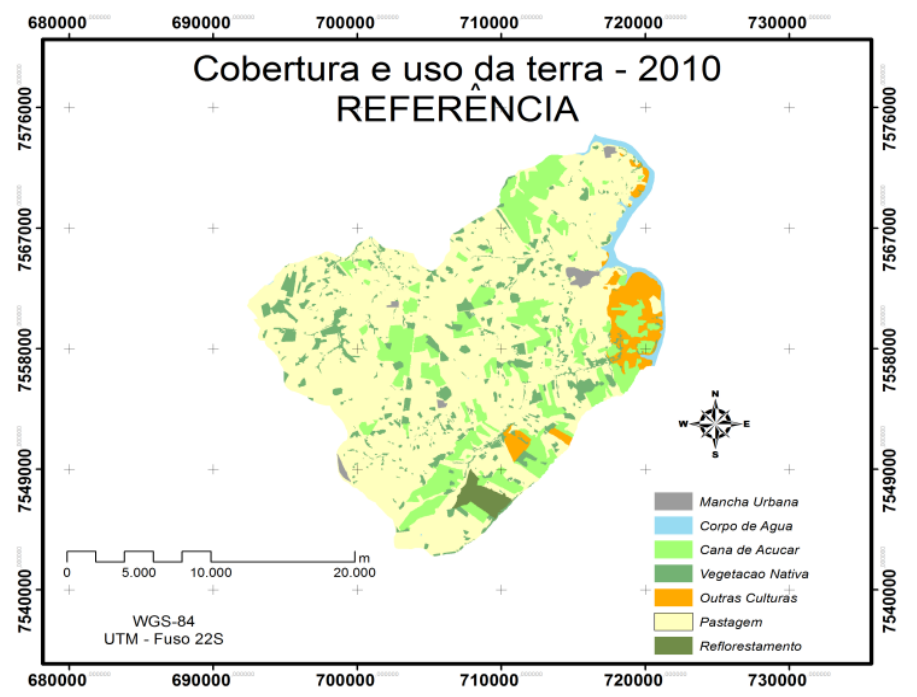

Bol. Ciênc. Geod., sec. Artigos, Curitiba, v. 19, nº 2, p.313-337, abr-jun, 2013. 


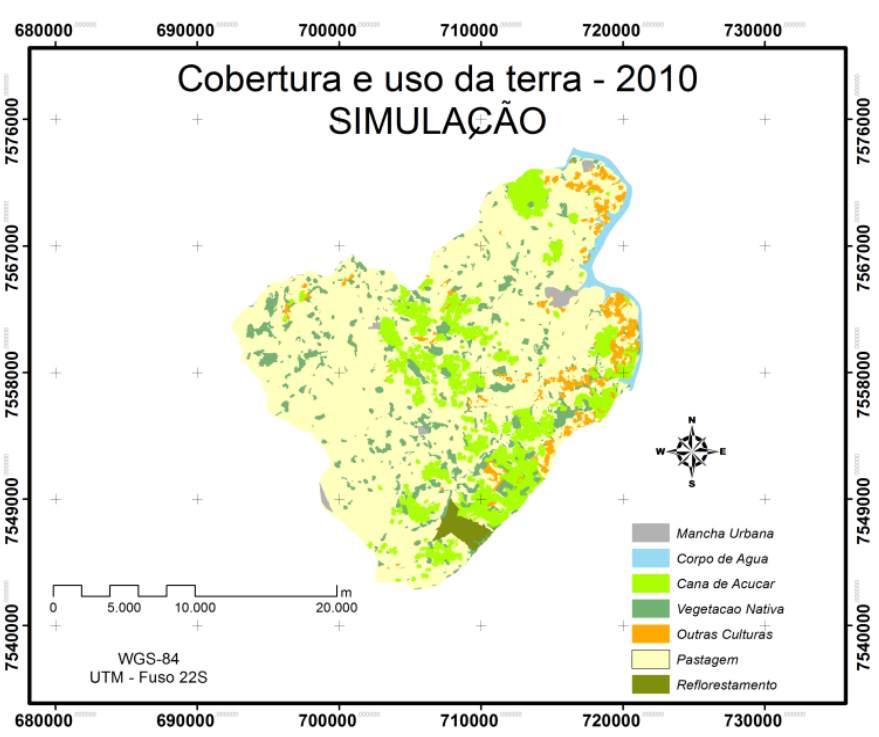

\section{CONCLUSÕES}

Os esforços para se calibrar o modelo levam a constantes (re) parametrizações, incluindo ciclos de seleção de variáveis e de cálculo dos pesos de evidência. Esta rotina cíclica conduz ao aprimoramento do conhecimento dos fatores direcionadores das mudanças de cobertura e uso da terra em Arealva, entre 2005 e 2010. Tal aprimoramento traz não só o conhecimento das forçantes, mas principalmente a possibilidade de uma ponderação menos arbitrária do que a realizada com consulta às partes interessadas (stakeholders).

No processo de expansão canavieira, a declividade e a distância aos cursos d'água apresentaram pesos maiores que o tipo de solo ou a distância às estradas. As dificuldades para a mecanização fazem com que a declividade apresente ponderação negativa. Atrelada a isto, a ausência de irrigação faz com que haja um certo direcionamento para áreas relativamente distantes dos cursos d'água e com condições mais favoráveis no que tange ao aproveitamento da propriedade e aos aspectos logísticos.

Em relação à degradação, a distância aos cursos d'água e às estradas e a declividade apresentaram pesos maiores que o tipo de solo. O rigor da fiscalização em relação às APPs e o relativo desinteresse da agropecuária nas áreas mais íngremes ajudam a explicar a ponderação negativa da declividade e da distância aos cursos d'água. A ponderação positiva relacionada à proximidade das estradas é compatível com a correlação empírica existente entre estradas e degradação.

As variáveis declividade (ponderação positiva) e "distância à vegetação nativa” (ponderação negativa) foram as que apresentaram maior peso para processos 
de regeneração. O fluxo gênico envolvido nos processos de polinização e no banco de sementes ajudam a explicar tal influência. Além disso, em locais íngremes, houve mais transições relacionadas à retração de atividades agropecuárias e regeneração de vegetação nativa.

Nos processos de retração, o algoritmo patcher teve uma importância maior que o algoritmo expander.

Acredita-se que a inclusão de variáveis socioeconômicas, como o preço da terra ou o valor das commodities, possa melhorar significativamente os resultados das simulações.

\section{AGRADECIMENTOS:}

Milaine Trabuco e Johannes Peter Feldenheimer, do Escritório de Desenvolvimento Regional de Bauru, pelo apoio institucional; Élcio Alves Macedo, da Casa da Agricultura de Arealva, pelo auxílio no levantamento de campo; Edson Crepani, Daniel Alves Aguiar e Moisés Salgado, do Laboratório de Sensoriamento Remoto Aplicado a Agricultura e Florestas, pelo auxílio com os dados hidrográficos; Aline Salim, da Secretaria do Meio Ambiente, pela disponibilização do mapa de uso do solo de 2005; Marco Nalon e Ciro Matsukuma, do Instituto Florestal, pela disponibilização do inventário florestal de 2008/2009; Celso Vainer Manzatto, da Empresa Brasileira de Pesquisa Agropecuária, pela disponibilização do zoneamento agroecológico da cana de açúcar; Ricardo Marques Coelho e Jener Fernando de Moraes, do Instituto Agronômico de Campinas, pela disponibilização do mapa de solos; CAPES, pelo suporte financeiro. Aos revisores, cujas críticas contribuíram para a melhora da qualidade final do artigo.

\section{REFERÊNCIAS BIBLIOGRÁFICAS}

ALMEIDA, C. L. F. de; OLIVEIRA, J. B. de; PRADO, H. do. Levantamento Pedológico Semidetalhado do Estado de São Paulo: Quadrícula de Jaú (SF22 Z-B-II). Escala 1:100.000. Campinas: Instituto Agronômico, 1982.

ALMEIDA, C. M. Modelagem da dinâmica espacial como uma ferramenta auxiliar ao planejamento: simulação de mudanças de uso da terra em áreas urbanas para as cidades de Bauru e Piracicaba (SP), Brasil. Tese de Doutorado em Sensoriamento Remoto. INPE, São José dos Campos, 2003. 321 p.

ALMEIDA, C. M.; GLERIANI, J. M.; CASTEJON, E. F.; SOARES-FILHO, B. S. Using neural networks and cellular automata for modeling intra-urban land use dynamics. International Journal of Geographical Information Science, v. 22, n. 9, p. 943-963, 2008.

AREALVA. Plano municipal de desenvolvimento rural sustentável 2010-2013. Prefeitura Municipal de Arealva. Conselho Municipal de Desenvolvimento Rural. Casa da Agricultura de Arealva. Escritório de Desenvolvimento Rural de Bauru. 2010.

BATTY, M. Urban modelling: Algorithms, calibrations, predictions. Cambridge, UK: Cambridge University Press. 1976. 
BATTY, M. Geocomputation using cellular automata. In: LONGLEY, P. A.; BROOKS, S. M.; McDONNELL, R.; MACMILLAN, B. (eds). Geocomputation: A Primer. John Wiley \& Sons Ltd., p. 95-126. 1998.

BONHAM-CARTER, G. F. Geographic Information Systems for Geoscientists: Modelling with GIS. Ontario: Pergamon, 1994. 305 p.

BRIASSOULIS, H. Analysis of Land Use Change: Theoretical and Modeling Approaches. Lescos, Grécia. Tese de Doutorado em Geografia - University of Aegean, 2000. Disponível em: $<$ http://www.rri.wvu.edu/WebBook/Briassoulis/contents.htm>. Acesso em janeiro de 2012. 2000.

BRINER, S.; ELKIN, C.; HUBER, R.; GRÊT-REGAMEY, A. Assessing the impacts of economic and climate changes on land-use in mountain regions: A spatial dynamic modeling approach. Agriculture, Ecosystems and Environment, v. 149, p. 50-63, 2012.

BRITZ, W.; VERBURG, P. H.; LEIP, A. Modelling of land cover and agricultural change in Europe: Combining the CLUE and CAPRI-Spat approaches. Agriculture, Ecosystems and Environment, v. 142, p. 40-50, 2011

BURROUGH, P. A. Dynamic Modelling and Geocomputation. In: LONGLEY, P. A.; BROOKS, S. M.; McDONNELL, R.; MACMILLAN, B. (Eds.). Geocomputation: A Primer. John Wiley \& Sons Ltd. p. 165-191. 1998.

COUCLELIS, H. Modeling frameworks, paradigms and approaches. In: CLARKE, K. C.; PARKS, B. O.; CRANE, M. P. (eds). Geographic information systems and environmental modeling. Upper Saddle River, NJ: Prentice Hall, p. 36-50. 2002.

EMBRAPA - EMPRESA BRASILEIRA DE PESQUISA AGROPECUÁRIA. Centro Nacional de Pesquisa de Solos. Sistema brasileiro de classificac ão de solos. Brasília: EMBRAPA Produc ão de Informac ão, Rio de Janeiro: EMBRAPA Solos, 1999. 412 p.

FOODY, G. M. Status of land cover classification accuracy assessment. Remote Sensing of Environment, v. 80, p. 185-201, 2002.

FOODY, G. M. Thematic map comparison: evaluating the statistical significance of differences in classification accuracy. Photogrammetric Engineering and Remote Sensing, v. 70, p. 627-633, 2004.

FREITAS, M. W. D.; SANTOS, J. R.; ALVES, D. S. Land-use and land-cover change processes in the Upper Uruguay Basin: linking environmental and socioeconomic variables. Landscape Ecology, v. 28, p. 311-327, 2013.

GEOGHEGAN, J.; PRITCHARD Jr., L.; OGNEVA-HIMMELBERGER, Y.; CHOWDHURY, R. R.; SANDERSON, S.; TURNER II, B. L. Socializing the Pixel and Pixelizing the Social in Land-Use and Land-Cover Change. p. 51-69. In: LIVERMAN, D.; MORAN, E. F.; RINDFUSS, R. R.; STERN, P. C. (Ed.). People and Pixels: Linking Remote Sensing and Social Science. National Academy Press, Washington, D.C, 1998. 267 p. 
GONÇALVES, D. A.; SOUSA JÚNIOR, W. C.; ALMEIDA, C. M. Modelagem de alteração de uso e cobertura da terra em uma porção do município de Mineiros-GO utilizando o método de pesos de evidência. In: XII Simpósio Brasileiro de Geografia Física Aplicada (XII SBGFA), UFRN, Natal/RN. 2007 13 p.

HAGEN, A. Multi-method assessment of map similarity. In: RUIZ, M., GOULD, M., RAMON, J. (Eds.), Proceedings of the Fifth AGILE Conference on Geographic Information Science, Palma, Spain, p. 171-182, 2002.

HAGEN, A. Fuzzy set approach to assessing similarity of categorical maps. International Journal of Geographical Information Science, v. 17, n. 3, p. 235249, 2003.

HUERTA, E.; MANGIATERRA, A.; NOGUERA, G. GPS. Posicionamiento Satelital. UNR, Argentina. 2005. 138 p.

IBGE - Instituto Brasileiro de Geografia e Estatística. Divisão Territorial do Brasil e Limites Territoriais. 2011a.

IBGE - Instituto Brasileiro de Geografia e Estatística. Base Cartográfica Contínua 1:250.000. 2011b.

IGBP/IHDP. Land Use and Land Cover: Implementation Strategy. IGBP Report, n. 48, IHDP Report, n. 10, Estocolmo: IGBP Secretariat. 1999.

INPE - Instituto Nacional de Pesquisas Espaciais. Divisão de Sensoriamento Remoto. CANASAT. Mapeamento da cana via imagens de satélite de observação da terra. São José dos Campos/SP. Disponível em $<$ http://www.dsr.inpe.br/canasat>. Acesso em: janeiro de 2011. 2011a.

INPE - Instituto Nacional de Pesquisas Espaciais. Divisão de Sensoriamento Remoto. TOPODATA. Banco de dados geomorfométricos do Brasil. São José dos Campos/SP. Disponível em <http://www.dsr.inpe.br/topodata>. Acesso em: janeiro de 2011. 2011b.

JENSEN, J. R. Introductory Digital Image Processing: A Remote Sensing Perspective. 3rd ed. Pearson Prentice Hall, New Jersey. 2005. 528 p.

KRONKA, F. J. N.; NALON, M. A.;MATSUKUMA, C. K.; KANASHIRO, M. M.; YWANE, M. S. S.; PAVÃO, M.; DURIGAN, G.; LIMA, L. M. P. R.; GUILLAUMON, J. R.; BAITELLO, J. B.; BORGO, S. C.; MANETTI, L. A.; BARRADAS, A. M. F.; FUKUDA, J. C.; SHIDA, C. N.; MONTEIRO, C. H. B.; PONTINHA, A. A. S.; ANDRADE, G. G.; BARBOSA, O.; SOARES A. P.; COUTO, H. T. Z. do; JOLY, C. A. Inventário florestal da vegetação natural do Estado de São Paulo. São Paulo: Imprensa Oficial, 2005. 200 p.

LAMBIN, E. F. ; ROUNSEVELL, M. D. A.; GEIST, H. J. Are agricultural land-use models able to predict changes in land-use intensity? Agriculture, Ecosystems and Environment, v. 82, p. 321-331, 2000

LEPSCH, I. F.; BELINAZZI JR., R.; BERTOLINI, D.; ESPINDOLA, C. R. Manual para levantamento utilitário do meio físico e classificac ão de terras no sistema de capacidade de uso. $4^{\mathrm{a}}$ ed. Campinas: SBCC, 1991. 175 p. 
MAEDA, E. E.; ALMEIDA, C. M.; XIMENES, A. C.; FORMAGGIO, A. R.; SHIMABUKURO, Y. E.; PELLIKKA, P. Dynamic Modelling of Forest Conversion: Simulation of Past and Future Scenarios of Rural Activities in the Fringes of the Xingu National Park, Brazilian Amazon. International Journal of Applied Earth Observation and Geoinformation, v. 13, p. 435-446, 2011.

MANZATTO, C. V.; ASSAD, E. D.; BACCA, J. F. M.; ZARONI, M. J.; PEREIRA, S. E. M. (Orgs.). Zoneamento Agroecológico da Cana-de-Açúcar: Expandir a produção, preservar a vida, garantir o futuro. EMBRAPA. Centro Nacional de Pesquisa de Solos. Ministério da Agricultura, Pecuária e Abastecimento. Rio de Janeiro, 2009. 58 p.

MARQUES, J. Q. A. Manual brasileiro para levantamento da capacidade de uso da terra: $3^{\mathrm{a}}$ ed. Escritório Técnico Brasil-Estados Unidos (ETA), 1971. 433 p.

MAS, J. F. Monitoring land-cover change: a comparison of change detection techniques. International Journal of Remote Sensing, v. 20, p. 139-152. 1999.

MATHER, P. M. Computer Processing of Remotely-Sensed Images: An Introduction. 3rd ed. John Wiley \& Sons, England. 2004. 326 p.

McCOY, R. M. Field Methods in Remote Sensing. The Guilford Press, New York. 2005. 178 p.

MEYER, W. B.; TURNER II, B. L. Land-Use/Land-Cover Change: Challenges for Geographers. Geojournal, v. 39, n. 3, p. 237-240. 1996.

MIKHAIL, E. M.; GRACIE, G. Analysis and Adjustment of Survey Measurements. VNR, New York. 1977. 340 p.

NOVAES, M. R. ; RUDORFF, B. F. T. ; ALMEIDA, C. M. ; AGUIAR, D. A. . Análise Espacial da Redução da Queima na Colheita da Cana-de-Açúcar: Perspectivas Futuras ao Cumprimento do Protocolo Agro-Ambiental. Engenharia Agrícola (Impresso), v. 31, p. 572-583, 2011.

OPENSHAW, S. Geocomputation. In: LONGLEY, P. A.; BROOKS, S. M.; McDONNELL, R.; MACMILLAN, B. (Eds.). Geocomputation: A Primer. John Wiley \& Sons Ltd., p. 1-29. 1998.

PÉREZ-VEGA, A.; MAS, J.; LIGMANN-ZIELINSKA, A. Comparing two approaches to land use/cover change modeling and their implications for the assessment of biodiversity loss in a deciduous tropical forest. Environmental Modelling \& Software, v. 29, p. 11-23, 2012.

PONTIUS JR., R. G. Quantification error versus location error in comparison of categorical maps. Photogrammetric Engineering and Remote Sensing, v. 66, n. 8, p. 1011-1016, 2000.

PONTIUS JR., R. G. Statistical methods to partion effects of quantity and location during comparison of categorical maps at multiple resolutions. Photogrammetric Engineering and Remote Sensing, v. 68, n. 10, p. 1041-1049, 2002.

SÃO PAULO (Estado). Comite da Bacia Hidrográfica do Tiete /Jacaré. Fundo Estadual de Recursos Hídricos. Instituto de Pesquisas Tecnológicas do Estado de São Paulo. Diagnóstico da situac ão atual dos recursos hídricos e 
estabelecimento de diretrizes técnicas para a elaborac ão do Plano da Bacia Hidrográfica do Tiete /Jacaré - Relatório Final. São Paulo: CBHTJ/FEHIDRO/IPT. 2000.

SÃO PAULO (Estado). Secretaria de Agricultura e Abastecimento. Coordenadoria de Assiste ncia Técnica Integral. Instituto de Economia Agrícola. Levantamento censitário de unidades de produc ão agrícola do Estado de São Paulo - LUPA 2007/2008. São Paulo: SAA/CATI/IEA, 2008. Disponível em: <http://www.cati.sp.gov.br/projetolupa>. Acesso em: 2012. 2008a.

SÃO PAULO (Estado). Secretaria do Meio Ambiente. Resolução SMA n. 88, de 19 de dezembro de 2008. 2008b.

SÃO PAULO (Estado). Secretaria do Meio Ambiente. Coordenadoria de Planejamento Ambiental. Mapa de uso e ocupação do Estado de São Paulo na escala 1:50.000. São Paulo: SMA/CPLA, 2009.

SÃO PAULO (Estado). Instituto Florestal. Inventário Florestal da Cobertura Vegetal Nativa do Estado de São Paulo, 2008-2009. 2010 (no prelo).

SÃO PAULO (Estado). Departamento de Águas e Energia Elétrica. Diretoria de Recursos Hídricos. Projeto GISAT. Base vetorial da malha hidrográfica. São Paulo: DAEE/DRH/GISAT, 2011.

SOARES-FILHO, B. S.; CERQUEIRA, G. C.; PENNACHIN, C. L. DINAMICA a stochastic cellular automata model designed to simulate the landscape dynamics in an Amazonian colonization frontier. Ecological Modelling, v. 154, p. 217-235. 2002.

SOARES-FILHO, B.; RODRIGUES, H.; FOLLADOR, M. A hybrid analyticalheuristic method for calibrating land-use change models. Environmental Modelling \& Software, v. 43, p. 80-87, 2013.

TURNER II, B. L.; SKOLE, D. L.; SANDERSON, S.; FISCHER, G.; FRESCO, L.; LEEMANS, R. Land-Use and Land-Cover Change: Science/Research Plan. IGBP Report, n. 35, IHDP Report, n. 7. IGBP e HDP, Estocolmo e Gênova, 1995.

VELDKAMP, A.; VERBURG, P. H.; KOK, K.; KONING, G. H. J.; PRIESS, J.; BERGSMA, A. R. The need for scale sensitive approaches in spatially explicit land use change modeling. Environmental Modeling and Assessment, v. 6, p. 111-121. 2001.

WIKIPEDIA - The Free Encyclopedia. Arealva. Disponível em: $<$ http://pt.wikipedia.org/wiki/Arealva>. Accesso em janeiro de 2013.

WOLFRAM, S. Universality and complexity in cellular automata. Physica, v. 10D, North-Holland, Amsterdam, p. 1-35. 1984.

XIMENES, A. C.; ALMEIDA, C. M.; AMARAL, S.; ESCADA, M. I. S.; AGUIAR, A. P. A. Modelagem dinâmica do desmatamento na Amazônia. Boletim de Ciências Geodésicas, v. 14, n. 3, Curitiba, p. 370-391. 2008.

(Recebido em março de 2013. Aceito em maio de 2013.) 